\title{
'Military Munchausen's': assessment of factitious claims of military service in psychiatric patients
}

\author{
Martin Baggaley
}

Thisteen per cent of referrals of ex-servicemen to a milltary poychiativic centre for the treatiment of combatrelated post-troumatic stress disorder (PISD) in a 12 month period have proved to be factitious. A simple clasesfication of factitious combat-related PTSD into those with no milltary service and those with milltary service but with false claims of combat is described. The poselble couses of this behoviour are discussed and a guide to the detection of factitious claims for poychiatrists without milltary experience is given.

In the past 12 months, the Defence Services Psychiatric Centre has been accepting referrals of ex-servicemen for the treatment of posttraumatic stress disorder (PTSD). A considerable number $(5 / 39,13 \%)$ of these referrals have proven to be factitious in a number of ways. Some of these patients had already passed some sort of military official prior to referral. If individuals are finding it possible to convince referrers with military experience, it is probable that the problem is more widespread in purely civilian settings. This is likely to be particularly so as the number of doctors with previous military service has diminished since those doctors who did National Service have mostly retired. There have been previous reports of Vietnam veterans feigning PTSD (Lacoursiere, 1993). There has been a previous case report of a factitious case of PTSD presenting to a military hospital in the UK (Neal \& Rose, 1995). Telephone enquiries from National Health Service units suggest that it is not uncommon for patients to present with dramatic stories of military trauma of questionable validity. Such behaviour is unhelpful for both patient and clinician and may cause resources and time to be wasted treating the wrong condition; for example, trying to treat non-existent PTSD instead of perhaps personality disorder, a psychotic disorder or substance misuse. This paper discusses the various different types of presentation and reviews the possible underlying diagnosis and motivation. Some simple guidance is given to assist psychiatrists in determining the veracity of claims of military service in their patients.

\section{Types of presentation}

Cases of factitious combat-related PTSD can be divided into two major groups: (a) those with no previous military service and (b) those with previous military service but with false claims of career details or of operational involvement.

Those with no military service can usually be detected very easily by service doctors because of obvious errors or lack of knowledge of cultural norms. For example one patient claimed to have held the rank of private in the Royal Engineers. In fact the rank of private in this regiment is known as 'sapper'. It can be harder if an individual has served but is altering slight details. Some such individuals can be difficult to detect, even by military doctors. This is particularly true if they have been to an operational area such as Bosnia and know of specific traumatic incidents which they can describe but may have not participated in.

\section{Aetiology}

The motivation behind such false claims varies. In some cases it is for possible financial gain. either from compensation for personal injury or from a war pension. In others it may be related to benefits of the sick role or to improve self-esteem. In some cases it may be an attempt to mitigate criminal behaviour. Cases of factitious PTSD need to be distinguished from individuals with military service who may genuinely but mistakenly attribute their service experience as a cause of their current psychiatric difficulties. For many, it is more acceptable to be psychiatrically ill because of war experience than due to more mundane causes. It may also facilitate entry or 
access to psychiatric care as clinicians may be more interested in disorders such as PTSD rather than other diagnoses.

\section{Assessment}

There are a number of clues which can raise suspicion of a factitious account.

"I've been in the SAS"

Recently there has been an explosion of books concerning the Special Air Service (SAS), for example Bravo Two Zero (McNab, 1994), which provide readers with considerable, accurate background knowledge. The SAS has a particular glamour which may attract individuals to claim to have served with the unit. The majority of factitious patients presenting to the Defence Services Psychiatric Centre have claimed to belong to some 'special forces' usually the SAS. Often this is introduced in hushed tones or using euphemisms such as 'Hereford', or the 'Unit'. A number claimed to have fought in the Gulf War and to have been imprisoned by the Iraqis. One claimed to have been both in the Gulf and the Falklands War. Experience in Northern Ireland is also a common theme, often in special or secret organisations. Claiming membership of the SAS, 'the Unit', serving at 'Hereford', on first meeting is always suspicious. Genuine members of the SAS are secretive and would not usually reveal their past to others without considerable trust being built up.

\section{"I can't say - it's secret"}

Patients claiming that they cannot tell about what happened "because it is classified", are also suspicious. People who have genuine classified information usually understand that they cannot say anything, so would steer away from mental health professionals in the first place. Claiming that their records will have been destroyed because what they did was so secret is also unlikely to be true.
"I cannot remember my Service number"

Servicemen usually never forget their number, so anyone who cannot remember or is uncertain about it is likely to be factitious. Officers (Captain, Lieutenant, etc.) have five figure numbers and other ranks (Private, Corporal, Sergeant) eight figures.

\section{Dramatic story telling}

Individuals who are found to be making false claims often describe the trauma in a melodramatic way, using clichés about for example combat, with an absence of physiological arousal while doing so, and inconsistent detail. In contrast, individuals with genuine combat related details describe horrific events without dramatic embellishment but with usual distress and physiological arousal.

\section{Confirmation of identity}

There are a number of ways a military history can be confirmed. It is highly unusual for servicemen or women to forget their number, unit and rank at discharge. With this information, it is possible to obtain records of military service, military medical records and whether they served in the SAS or not. Such enquiries can be made in the first instance to a local military establishment who would be able to direct the enquirer to the relevant record department. Alternatively queries can be directed to the Defence Services Psychiatric Centre, Catterick, North Yorkshire DL9 4DF.

\section{References}

LACOURSIERE. R. B. (1993) Diverse motives for factitious post traumatic stress disorder. Joumal of Traumatic Stress, 6, 141-149.

MCNAB. A. (1994) Bravo Two Zero. London: Corg1.

NEAL, L. A. \& Rose. M. C. (1995) Factitious post traumatic stress disorder: a case report. Medicine, Science and the Law. 35, 352-353.

Martin Baggaley, Consultant Psychiatrist, The Ladywell Unit, Lewisham Hospital, London SE13 6LH 